\title{
ENERGETIC INDICATORS FOR PLANNING AND PROJECTS IN THE KELLER PENINSULA
}

http://dx.doi.org/10.4322/apa.2014.117

Tiago Malavazi de Christo*, Jussara Farias Fardin, Domingos Sávio Lyrio Simonetti, Cristina Engel de Alvarez

Universidade Federal do Espírito Santo, Av. Fernando Ferrari, 514, Goiabeiras, Zip Code: 29075-910, Vitória, ES, Brazil

*e-mail: tmalavazi@ifes.edu.br

\begin{abstract}
This paper gathers information on the energetic profile of the Brazilian Antarctic Station and shows energetic indicators obtained during the study of the renewable resources potentials of the region. The technologies for generation and use of energy are also investigated and assessed, and a proposal of a hybrid energetic matrix is presented. The technologies for processing solid waste, cogeneration in internal combustion engines and in the incinerator, use of photovoltaic panels and wind turbines were assessed.
\end{abstract}

Keywords: Energetic Potentials, Renewable Energies, Hybrid Matrix, Cogeneration

\section{Introduction}

In order to support new projects in Keller Peninsula, this paper summarizes the main results obtained by Christo (2012). The energy consumption profiles in the Comandante Ferraz Antarctic Station (EACF, Portuguese acronym) and energetic potential from the use of solid waste, cogeneration, use of photovoltaic panels and wind turbines were studied. In addition to estimation of the energetic potentials, several compositions of hybrid energetic matrix were analyzed. The studies performed considers the liter of diesel oil as currency, thus the indicators that will be shown can be used both as indicators of performance and financial.

\section{Materials and Methods}

In order to know the fuel consumption profile and the electric profile of the EACF, both the fuel control and the electric charges spreadsheets, provided by Brazilian Navy, were assessed. The data was arranged in graphs and in percentage per group.

In the survey of EACF's energetic potentials the calculations for a 1-year period, with maximum resolution of the data were carried out and the annual volumes of fuels that can be saved by adoption of each technology were estimated.
The survey of monthly solid waste production was achieved by analysis of the Reports of Waste Generated in the EACF and the calculations presented by Woelffel et al. (2007).

The estimations of the daily thermal energy production in the set of electricity generator engines and the daily thermal energy demand in the boilers were carried out based on the data from fuel consumption control spreadsheet for the year 2011.

For estimation of the solar potential in the EACF region, the global horizontal radiation, the transparency index and the influence of albedo (ground reflectance) were assessed, based on the data from NASA (2011) and Laine (2007). A model of commercial photovoltaic panel was simulated in different positioning techniques fixed and variable, based in the methodology proposed by Altener-Greenpro (2004).

For estimation of the wind potentials, 26 years of meteorological data provided by National Institute for Space Research (INPE, Portuguese acronym) from the CPTEC/ Antarctic Meteorology Project (2010), was used. In addition to wind speeds and direction, the influence of temperature and pressure also were taken into account. The wind profile was obtained by the distribution of wind speeds frequencies 
and the modeling through Weibull distribution curve (Patel, 1999). The data of wind potential per square meter $\left(\mathrm{m}^{2}\right)$ of intercepted area was obtained and three commercial wind turbines models were assessed.

The graphical analysis of the wind resource was performed with the aid of a computer tool for analysis of winds WindGrapher 2.01. For graphical analysis of solar resource and the simulation of hybrids matrices the computer-based tool HOMER 2.81 was used. This tools uses modeling already validated by NREL - National Renewable Energy Laboratory (WindoGrapher, 2011; HOMER Energy, 2011). The simulation of several hybrid energy matrices compositions were assigned to three groups, according to the installed renewable potency and mean demand. The results of simulations were compared for: safety and reliability, fuel consumption, environmental impact and logistic effort.

\section{Results}

In the Comandante Ferraz Antarctic Station, the electricity were totally produced by diesel generators without heat recovery system, and the water heating were made by diesel boilers. The annual diesel oil consumption in 2011 was 358,985 liters, corresponding to 983.5 liters/day, on average. Figure 1 shows the 2011 electricity and thermal demands in EACF.

By analyzing Figure 1 and the occupation of the station, it was found that the diesel oil consumption for the generators is higher in summer and winter months, when there occurs respectively higher research activity and higher need for heating of water pipes and sewers. The higher Diesel oil consumption for the boilers was found in winter, when the thermal compensation must be higher due to reduced external temperatures.

The energetic diagnosis of the EACF performed in $2010 / 2011$ showed that $54 \%$ of the electricity was uncontrolled used for heating the water and sewers pipes, which represent the equivalent to $42 \%$ of the annual Diesel oil consumption. The highest consumers of fuels are the generator engine groups (78\%) and the boilers (18\%).

Potentials of organic solid waste and sewers: The solid waste and the sewer, depending on their characteristics, could be incinerated or processed into an Anaerobic Digestion system which consists of an organic matter conversion process in conditions of lack of oxygen (Reichert, 2005). In the EACF, $50 \%$ of the solid wastes are organic, and the remaining is composed of paper, plastic, metal and glass. The data surveyed from 30 days between November 2006 to March 2007 (summer period) exclusively related to food production and consumption process showed that in that period $573.6 \mathrm{~kg}$ of waste was generated reaching to $0.31 \mathrm{~kg} /$ inhabitant/day (Woelfell et al., 2007). From March 2009 to February 2010 the mean organic solid waste production was $640 \mathrm{~kg} / \mathrm{month}$. The use of a biodigester in the Station would eliminate the burning of Diesel oil from the incinerator and its emissions, and the methane produced could be used in the kitchen stoves or to generate extra thermal energy.

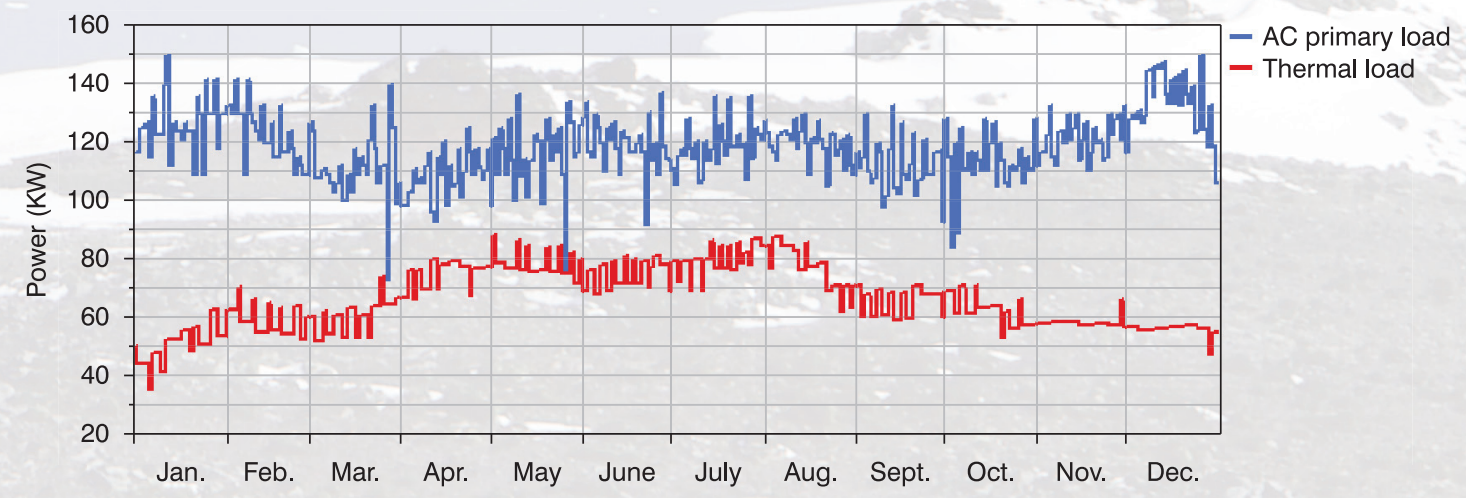

Figure 1. Demands of electric and thermal energy in the EACF in 2011 calculated from the spreadsheets provided by Brazilian Navy. AC Primary Load refers to the electricity demand. (Christo, 2012). 
However, the technology to be adopted should address three critical aspects: safety, temperature and water scarcity.

Potential of cogeneration: In a generator engine group powered by alternative internal combustion engines the quota of fuel that effectively is transformed into electric energy is around $36 \%$, which results in $64 \%$ of total losses. On the other hand, by using part of heat lost in gases of exhaust and of water and oil of engine cooling, the global energetic efficiency of the system can reaches $76 \%$ (Lora \& Nascimento, 2004). In the EACF, the mean daily consumption of the boilers in 2011 was about 150 liters/day in summer and 200 liters/day in winter, whereas thermal supply in the generators was about 350 liters/day in summer and 300 liters/day in winter. Although the thermal supply is higher than the demand, on average, the potential occurrence of instantaneous demands was found to be higher than the supply. This indicates the need for a system of storage of thermal energy from generator engine groups, to enable the maximum use of this source for calefaction and for the water heating system. The implantation of a cogeneration system into the incinerator was calculated too, it would represent a decrease about only $0.6 \%$ in the Station oil consumption.

Photovoltaic Energy Potential: The optimal angles found for fixed positioning were azimuth of $180^{\circ}$ and slope of $60^{\circ}$, resulting in a capacity factor of $10.8 \%$. For fixed panel and albedo of $70 \%$, the energy production is about $950 \mathrm{kWh}$ /year for each $1 \mathrm{kWp}$ placed (3 panels of $327 \mathrm{Wp}$, efficiency of $20.1 \%$ and coefficient of variation of potency equals to $-0.38 \% / \mathrm{C}^{\circ}$ ). The maximum decrease in Diesel consumption expected for the fixed positioning is 257 liters/year per installed kilowatt. In the optimal positioning screening technique, the capacity factor reached was $14.9 \%$; the energy generated was $1,309 \mathrm{kWh} /$ year $/ \mathrm{kWp}$, and the maximum decrease of consumption expected is 354.5 liters/year per installed kilowatt. The analysis of the influence of albedo showed that, when the albedo is equal to or higher than $70 \%$, the placement of panels in slopes angles higher that $60^{\circ}$ (for example, on the walls of the buildings) is possible with little decreases in annual photovoltaic energy production (-3,3\% for an $80^{\circ}$ inclination).

Wind Energy Potential: The Comandante Ferraz Antarctic Station is located in coastland, with annual mean wind speed equal to $6.1 \mathrm{~m} / \mathrm{s}$ and predominant directions north and west. The months with higher and lower average of winds recorded mean speeds of $9.5 \mathrm{~m} / \mathrm{s}$ in February of 1984 and $3 \mathrm{~m} / \mathrm{s}$ in January of 2005 (CPTEC, 2010). The modeling of wind data through Weibull distribution curve showed that " $\mathrm{k}$ " shaped parameter is situated about 1.45 , ranging from 1.37 to 1.59 , and the "c" scale parameter was situated in about $6.72 \mathrm{~m} / \mathrm{s}$, ranging from $5.34 \mathrm{~m} / \mathrm{s}$ up to $8.19 \mathrm{~m} / \mathrm{s}$, of summer to winter. The density of annual mean potency found was $398.4 \mathrm{~W} / \mathrm{m}^{2}$, with lower and upper mensal thresholds of $194.4 \mathrm{~W} / \mathrm{m}^{2}$ and $760.3 \mathrm{~W} / \mathrm{m}^{2}$, respectively. The annual rate of decrease of fuel consumption per installed peak kilowatt were between 729 liters/year/ $\mathrm{kWp}$ and 970 liters/year/kWp, respectively for the capacity factors of $30,7 \%$ and $40,9 \%$.

Hybrid Matrix Proposal: The possible configurations of hybrid energetic matrices were obtained by evaluating the Installed Renewable Potency (IRP) regarding to Mean Demand (MD) in the following conditions: IRP $<M D$, $I R P \cong M D$ and IRP $>M D$. Diesel-Solar-Wind hybrid settings with IRP $<$ MD showed to be particularly attractive due to there being no need for using batteries or extra energy storage system, has lower cost and lower complexity for placement and maintenance in Antarctic regions. Solutions with $\mathrm{IRP} \cong \mathrm{MD}$ and $\mathrm{IRP}>\mathrm{MD}$ showed less Diesel oil consumption, however they require damping systems for stability under variations of power flows, technologies for storing energy surpluses and largest areas for installation. Based on these three cases, 81 matrix compositions were simulated and evaluated considering their performance, reliability, technical feasibility and environmental impact. From this analysis was chosen the more attractive matrix for 2011 EACF demand, one particular composition of the IRP $<\mathrm{MD}$ case. Figure 2 shows a proposal of energetic matrix with three Diesel generators (Generators 1, 2 and emergency), four wind turbines $(4 \mathrm{x} 15 \mathrm{kWp})$ and 45 solar panels (45x327Wp), totaling $74,7 \mathrm{kWp}$ of installed renewable potency. Considering the maximum and minimum values for the annual mean speed already recorded in the EACF region $(4.6 \mathrm{~m} / \mathrm{s}$ and $7.1 \mathrm{~m} / \mathrm{s})$, the expected fuel consumption for this matrix will be between 236,659 liters/year (+6.8\%, for average winds of $4.6 \mathrm{~m} / \mathrm{s}$ ) and 213,329 liters/year (-3.6\%, for average winds of $7.1 \mathrm{~m} / \mathrm{s}$ ). The decrease in consumption reached in the simulation was $37 \%$ (137,576 liters/year). 


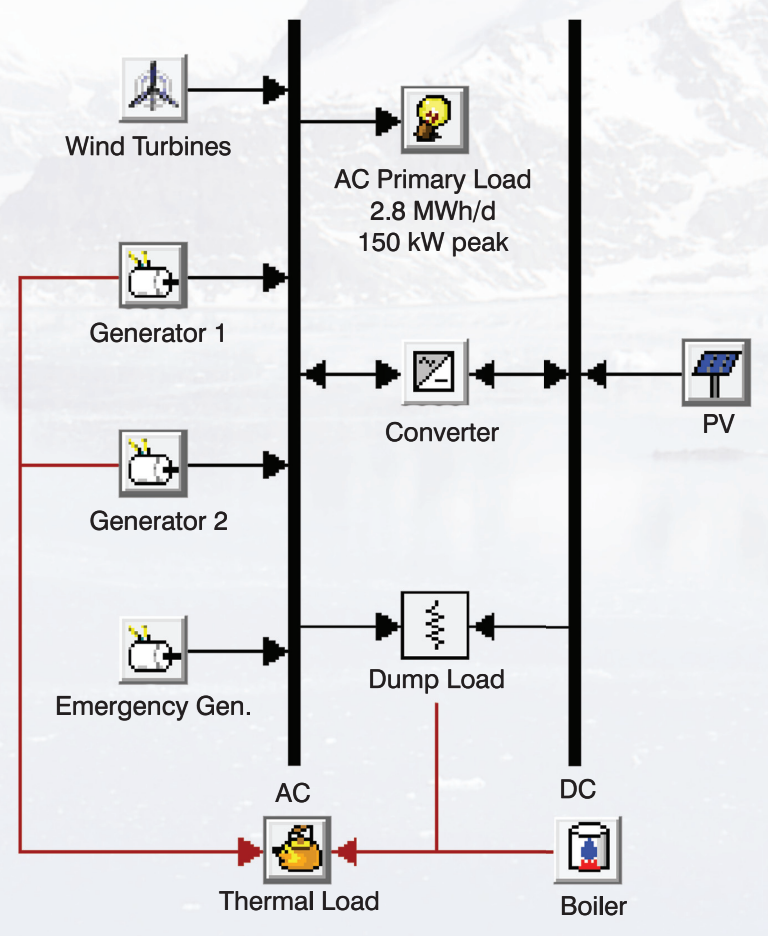

Figure 2. Proposed hybrid energetic matrix designed for the thermal and electrical loads profile of 2011 EACF. Adapted from Christo (2012).

\section{Discussion}

By assessing the electric demand of the EACF in 2011, it should be taken into account that about $50 \%$ of consumption are from circuits of heating cables subject to efficiency improvement. The anaerobic digestion may produce methane enough to use in the kitchen, however safety and operation temperature aspects of the anaerobic digester should be investigated. The use of Diesel-Electric boilers coupled with multiple thermal reservoirs could allow renewable matrices with percentage of penetration higher than $100 \%$, with no use of electric batteries, provided that there is an adequate management system. In addition the excess heat from cogeneration could be used for recirculation and thermal maintenance of the lake water pipes. Despite the use of wind turbines be interesting, must be performed detailed studies of soil to the correct fixation of turbines.

\section{Conclusion}

The indicators obtained show a suitability of using renewable energies in Keller peninsula. The study showed that in 2011 the supply of thermal energy was on average always higher than the demand, becoming more than twice during the summer. The use of wind turbines presented a capacity factor of about three times higher than the use of photovoltaic panels. A proposal of Solar-Wind-Diesel matrix for EACF was introduced, indicating a potential for reducing $37 \%$ of Diesel oil consumption, even with no use of batteries. As a way to continue the studies, a costs evaluation of the logistic, implementation and maintenance of the solutions presented here is suggested, especially taking into account the construction of new buildings for the EACF.

\section{Acknowledgements}

This work integrates the National Institute of Science and Technology Antarctic Environmental Research (INCT-APA) that receives scientific and financial support from the National Council for Research and Development (CNPq process: $n^{\circ}$ 574018/2008-5) and Carlos Chagas Research Support Foundation of the State of Rio de Janeiro (FAPERJ $\left.\mathrm{n}^{\circ} \mathrm{E}-16 / 170.023 / 2008\right)$. The authors also acknowledge the support of the Brazilian Ministries of Science, Technology and Innovation (MCTI), of Environment (MMA) and InterMinistry Commission for Sea Resources (CIRM).

\section{References}

Altener-Greenpro. (2004). Energia Fotovoltaica - Guia sobre tecnologia, projecto e instalação. Available from: <http://www. greenpro.de/po/fotovoltaico.pdf>. (Acesso: 2010).

Christo, T. M. (2012). Uma proposta de matriz energética para a Estação Antártica Comandante Ferraz: uma experiência aplicável a novas edificações. Dissertação de Mestrado em Engenharia Elétrica, Universidade Federal do Espírito Santo. $198 p$. 
CPTEC / Projeto de Meteorologia Antártica (2010). Projeto de Meteorologia Antártica/CPTEC. Available from: <http://antartica. cptec.inpe.br/>. (Acesso: 18 Abril 2010).

HOMER Energy (2011). Ferramenta para otimização de redes de potência hibridas. Available from: <http://www.homerenergy. com/>. (Acesso: 2011).

Laine, V. (2007). Antarctic ice albedo, temperature and sea ice concentration trends, 1981-2000. Annals of 2007 EUMETSAT Meteorological Satellite Conference and 15th AMS Conference, Amsterdam, The Netherlands. p. 50.

Lora, E. E. S. \& Nascimento, M. A. R. (2004). Geração termelétrica: planejamento, projeto e operação. Rio de Janeiro: Interciência.

NASA. (2011). NASA's Surface Solar Energy Data Set. Available from: <http://eosweb.larc.nasa.gov/sse/>. (Acesso: 2011).

Patel, M. R. (1999). Wind and Solar Power Systems. New York: CRC Press.

Reichert, G. A. (2005). Aplicação da Digestão Anaeróbia de Resíduos Sólidos Urbanos: Uma Revisão, Porto Alegre-RS. Anais do $23^{\circ}$ Congresso Brasileiro de Engenharia Sanitária e Ambiental - CBESA, 2005, Campo Grande-MS. p III-242.

WindoGrapher (2011). Ferramenta para análise gráfica de ventos. Available from: <http://www.windographer.com/> (Acesso: 2011).

Woelffel, A. B., Alvarez, C. E., Soares, G. R. \& Cruz, D. O. (2007). Resíduos sólidos gerados pelas atividades de produção e consumo de alimentos na Estação Antártica Comandante Ferraz, Vitória-ES. VII Seminário Estadual sobre Saneamento e Meio Ambiente, SESMA, 2007, Vitória-ES. 